\title{
Infectious Complications After Heart Transplantation in Chinese Recipients
}

\author{
Ron-Bin Hsu ${ }^{b}$, Chi-Tai Fang ${ }^{a}$, Shan-Chwen \\ Chang ${ }^{a}$, Nai-Kuan Choub, Wen-Je Ko ${ }^{b}$, \\ Shoei-Shen Wang ${ }^{b, *}$ and Shu-Hsun Chu ${ }^{b}$ \\ a Department of Surgery and ${ }^{\mathrm{b}}$ Internal Medicine, National \\ Taiwan University Hospital, National Taiwan University \\ College of Medicine and Far-Eastern Memorial Hospital, \\ Taipei, Taiwan \\ * Corresponding author: Shoei-Shen Wang, \\ sswang@ha.mc.ntu.edu.tw
}

\begin{abstract}
Several factors appear to influence the incidence and type of infectious complications among different populations of transplant recipients. This study sought to assess the incidence and type of infection after transplantation in Chinese heart allograft recipients. A total of 130 infectious episodes occurred in 192 consecutive heart transplantation patients between June 1993 and May 2004. The median length of follow-up was $46.7 \pm 38.4$ months. The 1-, 5- and 10-year survival rates were $81.8 \pm 2.8 \%, 63.0 \pm 3.8 \%$ and $45.7 \pm$ $7.7 \%$. Infection was the leading cause of early and late deaths. Of the infectious episodes, $66(51 \%)$ were caused by bacteria, $35(27 \%)$ by viruses, $10(8 \%)$ by fungi, $7(5 \%)$ by Mycobacterium tuberculosis and 12 $(9 \%)$ by other pathogens. The most common bacterial infectious episodes were caused by methicillinresistant Staphylococcus aureus (20 of 66). The most common viral infections were varicella zoster virus infection in $12(34 \%)$, cytomegalovirus infection in 9 $(26 \%)$ and hepatitis $B$ virus infection in $8(23 \%)$. There was only one episode of clinical syndrome compatible to Pneumocystis jiroveci pneumonia. In conclusion, there was low incidence of Pneumocystis jiroveci pneumonia and cytomegalovirus infection, and high incidence of Mycobacterium tuberculosis infection in Chinese heart allograft recipients.
\end{abstract}

Key words: Chinese, heart transplantation, infection

Received 17 January 2005, 9 March 2005 and accepted for publication 14 March 2005

\section{Introduction}

Infection is a common cause of morbidity and mortality in patients with heart transplantation (1-4). Early infections within the first month after transplantation are usually caused by nosocomial pathogens, such as Pseudomonas aeruginosa, Staphylococcus aureus and some Enterobacteriaceae. The sites of infection include blood, respiratory tract, urinary tract and surgical wounds. Late infections, occurring after the first month and within the first year of transplantation, are commonly caused by cytomegalovirus, Pneumocystis jiroveci, Legionella and fungi $(1,5)$.

Several factors appear to influence the incidence and type of infectious complications among different populations of transplant recipients. They included the type, duration and intensity of the immunosuppressive drugs, geographic differences in the exposure to community and hospitalacquired pathogens and the introduction of prophylactic antimicrobial strategies after transplantation $(1,6)$. The purpose of this study was to assess the incidence of infectious complications in heart transplantation recipients at our hospital and to evaluate the difference between western and Chinese population.

\section{Patients and Methods}

\section{Patient population}

A total of 192 consecutive patients who underwent heart transplantation from June 1993 through May 2004 at National Taiwan University Hospital were included. Pre-transplantation clinical and demographic information on the transplant recipients and donors, type of immunosuppression, type of perioperative infectious prophylaxis, follow-up clinical information, and incidence and type of infectious episodes were collected and recorded. The infections were listed according to type of organism (bacterium, virus, fungus, parasite), location of infection, time of onset of infection after transplantation and clinical outcome. Serological screening for cytomegalovirus, Toxoplasma gondii, hepatitis B antigens and antibodies, human immunodeficiency virus antibody and hepatitis $C$ antibody was performed for donors and recipients. Tuberculin skin test was not routinely performed. Patients with previous history of tuberculosis or imaging evidence of pulmonary tuberculosis were excluded for transplantation.

\section{Immunosuppression}

All patients received triple-drug immunosuppressive therapy according to our heart transplantation protocol previously described (7). Since 1995, we started to use rabbit antithymocyte globulins for induction therapy. Azathioprine $(4 \mathrm{mg} / \mathrm{kg})$ was given $1 \mathrm{~h}$ before the operation. Solumedrol $(1000 \mathrm{mg})$ was infused while release of the aortic cross-clamp. Rabbit antithymocyte globulin (1.5-2.5 mg/kg/day) was given after transplantation for 5 days. Cyclosporine was started orally within 5 days after transplantation or after the recovery of renal function. Cyclosporine dose was adjusted according to renal function and serum cyclosporine level, which was maintained at the trough level of $300-500 \mathrm{ng} / \mathrm{mL}$ during the first 3 months after transplantation and $200-300 \mathrm{ng} / \mathrm{mL} 1$ year after transplantation. Azathioprine was given 


\section{Hsu et al.}

at $1-2 \mathrm{mg} / \mathrm{kg} /$ day after transplantation, with the dose adjusted to maintain a white blood cell count $4000-6000 / \mathrm{mm}^{3}$. Prednisone $(0.5 \mathrm{mg} / \mathrm{kg} / \mathrm{day})$ was started on the second postoperative day and tapered to $0.2 \mathrm{mg} / \mathrm{kg} / \mathrm{day}$ by the first month after transplantation. Tacrolimus (FK-506) and mycophenolate mofetil (Cellcept) were used for recurrent rejection or severe adverse reactions to cyclosporine and azathioprine. Since 2004, we started to use mycophenolate mofetil for primary immunosuppression instead of azathioprine. To prevent nephrotoxicity, cyclosporine dose was decreased to maintain serum trough level of $250-350 \mathrm{ng} / \mathrm{mL}$ during the first 3 months after transplantation and $150-250 \mathrm{ng} / \mathrm{mL} 1$ year after transplantation.

All patients were followed monthly at special cardiac transplantation clinic. Standard chest roentgenogram, blood tests, electrocardiogram and physical examinations were routinely performed at regular intervals. The mean follow-up duration was $46.7 \pm 38.4$ months. None of them was lost to follow-up.

\section{Prophylactic regimen}

Perioperative prophylactic antibiotics included $1 \mathrm{~g}$ of cefazolin given intravenously to recipients every $8 \mathrm{~h}$ until removal of endotracheal tube and drain tubes. In an attempt to prevent oropharyngeal candidiasis, mycostatin suspension (5 cc, 'swish and swallow') was given orally four times a day for 1 month after transplantation. Acyclovir 200 mg every $6 \mathrm{~h}$ was used for prophylaxis against herpes simplex virus and varicella zoster virus for 1 month after transplantation. No prophylactic agents were used for prevention of Pneumocystis jiroveci infection and Mycobacterium tuberculosis infection. Trimethoprim-sulfamethoxazole prophylaxis (one doublestrength tablet twice a day) was given for 6 months after transplantation in those patients who were seropositive for Toxoplasma gondii or received donors seropositive for Toxoplasma gondii. If the recipients had positive cytomegalovirus antibody preoperatively, no specific prophylaxis was given. Intravenous ganciclovir has been administered after transplantation for 1 month only in those cases in which the donor is positive and the recipient is negative for cytomegalovirus antibodies. These patients also received intravenous human cytomegalovirus immunoglobulin for 6 weeks.

\section{Post-transplantation outcome}

Major post-transplant events were categorized as 'acute rejection', 'infection' and 'transplant coronary artery disease'. Blood, urine and sputum culture specimens were taken when indicated by the presence of fever or suspected infection. Chest radiographs were obtained daily until the transplant recipient's cardiopulmonary status stabilized and 2-3 times weekly thereafter, until discharge from the hospital.

Bacterial infections were diagnosed by routine methods. The diagnosis of bacterial pulmonary infection required the presence of new or worsening pulmonary infiltrates and growth of organisms in cultures of sputum samples. The diagnosis of urinary tract infection was diagnosed on the basis of the finding of associated symptoms, pyuria and a positive urine culture. The diagnosis of fungal infection required histologic evidence of tissue invasion or isolation from blood or an otherwise sterile site. Diagnosis of viral infection required a significant rise in serological test titer (a four-fold rise in serial serum samples) and/or one of the following: a newly positive lgM antibody titer associated with clinical evidence of disease requiring antiviral therapy; seroconversion; virus isolation or histopathologic evidence of the virus. The isolated finding of a rise in serological test titer without signs or symptoms and not requiring antiviral therapy was not used as a criterion of active viral infection. Cytomegalovirus disease was defined as patients who had clinical or pathological manifestations of infection and cytomegaloviurs infection as patients who have only serological or virological evidence of infection with or without disease. Cytomegalovirus antigen was not routinely used for diagnosis of cytomegalovirus disease. Infections caused by Pneu- mocystis jiroveci or Toxoplasma gondii were diagnosed by characteristic cytological and/or histologic findings. All consecutive infectious episodes in each transplant recipient were included. Mild infections treated in the outpatient setting were not included in the present series.

\section{Statistical analysis}

The results are expressed as median with a range or as frequencies for the categorical variables. The survival curve was plotted by the KaplanMeier method. Statistical differences between groups were calculated using Fisher exact test. Differences were considered significant at $p<0.05$.

\section{Results}

\section{Patients}

From 1993 to 2004, 192 consecutive patients underwent cardiac transplantation for end-stage heart disease. The median age of the recipients was 48.45 years (range: $0.1-$ 70.8). Of the 192 patients, 155 (81\%) were males and $37(19 \%)$ were females; 5 patients (3\%) underwent retransplantation because of acute allograft rejection in two patients and transplant coronary artery disease in three patients. Three patients underwent heterotopic heart transplantation because of poor donor heart in two patients and high pulmonary vascular resistance in one patient. Five patients underwent simultaneous heart and kidney transplantation.

Diagnosed underlying heart diseases among the recipients included idiopathic dilated cardiomyopathy in 97 (51\%), coronary artery disease in 60 (31\%), valvular heart disease in $13(7 \%)$, congenital heart disease in $10(5 \%)$, postpartum cardiomyopathy in $3(2 \%)$, transplant coronary artery disease in $3(2 \%)$, restrictive cardiomyopathy in $2(1 \%)$, acute allograft rejection in $2(1 \%)$ and primary amyloidosis and primary cardiac tumor each in 1 patient. No patients had radiological evidence of pulmonary tuberculosis and serological evidence of human immunodeficiency virus infection. No patients ever received antituberculous therapy before transplantation.

The causes of early death ( $<30$ days after transplantation) were infection in seven patients, surgical bleeding in five patients, acute rejection in three patients and major stroke in one patient. The causes of late death ( $>30$ days after transplantation) were infection in 16 patients, transplant coronary artery disease in 10 patients, acute rejection in 8 patients, malignancy in 3 patients and others in 10 patients. Infection was the leading cause of early death and late death. The 1-, 5- and 10-year survival rates by KaplanMeier method were $81.8 \pm 2.8 \%, 63.0 \pm 3.8 \%$ and $45.7 \pm$ $7.7 \%$.

\section{Infectious episodes}

During the study period, 130 infectious episodes occurred in the 192 patients and the average episode per patient was 0.68 . A total of $66(51 \%)$ of the infectious episodes were bacterial, 35 (27\%) were viral, 10 (8\%) were fungal, 7 (5\%) 
were Mycobacterium tuberculosis and 12 (9\%) by other pathogens. The sites of infectious episodes were blood in $38(29 \%)$, lung in 27 (21\%), skin in $23(18 \%)$, superficial or deep sternal wound in $12(9 \%)$, urine in $11(8 \%)$, liver in 9 (7\%), eye in $2(1 \%)$, joint in $2(1 \%)$, lymph nodes in $2(1 \%)$, central nervous system in $2(1 \%)$ and stool and paranasal sinus each in 1 patient.

The most common bacterial infectious episodes were caused by methicillin-resistant Staphylococcus aureus (20 of 66). Gram-positive bacteria, particularly Staphylococcus species, accounted for $45 \%$ of 66 bacterial infections. Gram-negative bacteria, most commonly Klebsiella pneumoniae and Pseudomonas aeruginosa, accounted for 39\% of 66 bacterial infections.

The most common viral infections were varicella zoster virus infection in 12 (34\%), cytomegalovirus infection in $9(26 \%)$ and hepatitis B virus infection in $8(23 \%)$. There was only one case of primary varicella zoster virus infection (chickenpox) in a 10-year-old girl. She underwent emergency heart transplantation without varicella prophylaxis because of decompensated heart failure. Among the 11 herpes zoster infections, all were localized disease and occurred ranging from 6 to 95 months (median, 33) after transplantation. Among the nine cytomegalovirus infections, focal cytomegalovirus disease occurred in five patients as retinitis in two, pneumonia in one, hepatitis in one and skin in one patient. The onset time of cytomegalovirus infections ranged from 2 days to 28 months (median: 10 months) after transplantation. A total of 14 patients had trimethoprim-sulfamethoxazole prophylaxis for Toxoplasma gondii after transplantation. There was no infection caused by Toxoplasma gondii.

Cytomegalovirus serological test results were available for 183 donors; 171 (93\%) of them were positive for cytomegalovirus-specific lgG antibodies. Results of cytomegalovirus serological tests were available for 163 recipients; 121 (74\%) were positive preoperatively. Cytomegalovirus serological test results were available for 160 donor/recipient (D/R) pairs; of these, $3(2 \%)$ were $\mathrm{D}-/ \mathrm{R}-, 8$ (5\%) D-/R+, 37 (23\%) D+/R- and 112 (70\%) $\mathrm{D}+/ \mathrm{R}+$. Intravenous ganciclovir has been administered after transplantation in only 10 patients in which the donor is positive and the recipient is negative for cytomegalovirus antibodies. The other $27 \mathrm{D}+/ \mathrm{R}-$ patients did not have intravenous ganciclovir because of patient factors or economic problems. Cytomegalovirus infection developed in one $\mathrm{D}-/ \mathrm{R}$ - patients (33\%), $0 \mathrm{D}-/ \mathrm{R}+$ patients $(0 \%)$, five $D+/ R+$ patients $(4 \%)$ and one $D+/ R-$ patients $(3 \%)$. The serologic data were unclear in two patients with posttransplant cytomegalovirus infection.

Hepatitis B virus serological test results were available for 190 donors; 31 (16\%) of them were positive for hepatitis $B$ virus surface antigen. Results of hepatitis B virus serologic tests were available for 191 recipients; 13 (7\%) were positive for hepatitis B virus surface antigen and 26 (14\%) were negative for both hepatitis B virus antigen and antibodies preoperatively. Eight patients with hepatitis virus infection were successfully controlled with lamivudine therapy. Among the 31 hearts from donors positive for hepatitis $B$ virus surface antigen, 28 were given to recipients either positive for hepatitis $B$ virus surface antigen or positive for hepatitis $B$ virus antiboby. Three recipients who were negative for hepatitis $B$ virus received hearts from donors positive for hepatitis $B$ virus surface antigen and one patient developed hepatitis $B$ virus infection 9 months after transplantation.

\section{Pneumocystis jiroveci pneumonia}

There was only one episode of clinical syndrome compatible to Pneumocystis jiroveci pneumonia. This patient was a 45-year-old diabetic male. He underwent orthotopic heart transplantation because of end-stage coronary artery disease. The postoperative course was smooth and there was no acute rejection. Maintenance immunosuppression included cyclosporine, mycophenolate mofetil and prednisolone. However, he had fever, severe dyspnea and rapidly progressive pneumonia 5 months after transplantation. High-resolution computed tomography of the chest showed ground-glass pattern of bilateral pulmonary infiltration. Bronchoalveolar lavage and lung biopsy were not performed because of severe hypoxemia. He was treated as Pneumocystis jiroveci pneumonia and received trimethoprim-sulfamethoxazole. Intravenous ganciclovor was also given because of concurrent cytomegalovirus infection during treatment. He recovered slowly and was followed at out patient clinic for 2 months after treatment.

\section{Mycobacterium tuberculosis}

Of the 130 infectious episodes, 7 cases were caused by Mycobacterium tuberculosis. Patient data were listed in Table 1. The median onset of time was 38 months (range: 3-85). Three patients had extrapulmonary infection. No patient died of severe infection.

\section{Comparison with western series}

The comparison of patient characteristics and incidence of infectious episodes after transplantation was listed on Table 2. Only those series published after 1990 was listed for comparison (1,4,8-10). The incidences of common pathogens were compared between our Hsu's series, Stanford's series (1) and Miller's series of multicenter registry (4). In our patients, there was a significantly low incidence of Pneumocystis jiroveci pneumonia $(p<0.001$ between Hsu and Stanford; $\mathrm{p}=0.223$ between Hsu and Miller by Fisher exact test) and cytomegalovirus infection ( $p<0.001$ between Hsu and Stanford; $p<0.001$ between Hsu and Miller by Fisher exact test), but high incidence of Mycobacterium tuberculosis infection ( $p=0.002$ between Hsu and Stanford; $\mathrm{p}<0.001$ between Hsu and Miller by Fisher exact test). 
Hsu et al.

Table 1: Patient data in seven patients with Mycobacterium tuberculosis infection

\begin{tabular}{|c|c|c|c|c|c|c|c|}
\hline No. & $\begin{array}{l}\text { Age } \\
\text { (years) }\end{array}$ & Sex & $\begin{array}{l}\text { Medical comorbidities before } \\
\text { and after transplant }\end{array}$ & $\begin{array}{l}\text { Months after } \\
\text { transplant }\end{array}$ & Immunosuppression & $\begin{array}{l}\text { Site of } \\
\text { infection }\end{array}$ & $\begin{array}{l}\text { Outcome after } \\
\text { infection }\end{array}$ \\
\hline 1 & 66 & $M$ & $\begin{array}{l}\text { Diabetes mellitus, } \\
\text { prostate carcinoma }\end{array}$ & 85 & $\mathrm{C}, \mathrm{M}$ & Lung & Died 7 months carcinoma \\
\hline 2 & 62 & M & None & 62 & $C, M, P$ & Lung, joint & Alive 24 months \\
\hline 3 & 68 & $\mathrm{~F}$ & Anemia & 67 & $\mathrm{C}, \mathrm{M}, \mathrm{P}$ & Lung & Alive 15 months \\
\hline 4 & 64 & M & $\begin{array}{l}\text { Diabetes mellitus, } \\
\text { uremia, hypertension }\end{array}$ & 37 & $\mathrm{~T}, \mathrm{P}$ & Lung, intestine & Alive 11 months \\
\hline 5 & 66 & M & Hypertension & 18 & $\mathrm{~T}, \mathrm{M}$ & Lung & Alive 22 months \\
\hline 6 & 56 & M & Diabetes mellitus & 38 & C, M, P & Lung, joint & Alive 2 months \\
\hline 7 & 44 & M & None & 3 & $T, P$ & Lung & Alive 93 months \\
\hline
\end{tabular}

Table 2: Comparison of post-transplant infections between Taiwan and western patients

\begin{tabular}{|c|c|c|c|c|c|c|}
\hline Author & $\mathrm{Hsu}$ & Montoya & Cisneros & Grossi & Waser & Miller \\
\hline Year of publication & 2005 & 2001 & 1998 & 1992 & 1994 & 1994 \\
\hline Country & Taiwan & USA & Spain & Italy & Switerland & USA \\
\hline Patient number & 192 & 620 & 307 & 662 & 100 & 814 \\
\hline Age in years (mean) & $45.1 \pm 16.8$ & 40.4 & NA & NA & $44.8 \pm 11.6$ & $48.1 \pm 14.4$ \\
\hline Male & $81 \%$ & $78 \%$ & NA & NA & $92 \%$ & $80 \%$ \\
\hline Dilated cardiomyopathy & $51 \%$ & $39 \%$ & NA & NA & $46 \%$ & $38 \%$ \\
\hline Follow-up in months (median) & 43.8 & NA & NA & NA & $21.7 \pm 15.5$ & 8.2 \\
\hline \multicolumn{7}{|l|}{ Crude incidence } \\
\hline Cytomegalovirus* & $9(4.7 \%)$ & $141(22.7 \%)$ & $20(6.5 \%)$ & $58(8.8 \%)$ & $16(16 \%)$ & $108(13.3 \%)$ \\
\hline Mycobacterium tuberculosis* & $7(3.6 \%)$ & $3(0.5 \%)$ & $3(1 \%)$ & $4(0.6 \%)$ & NA & $1(0.1 \%)$ \\
\hline Pneumocystis jiroveci** & $1(0.5 \%)$ & $43(6.9 \%)$ & $11(3.6 \%)$ & $7(1.0 \%)$ & $4(4 \%)$ & $17(2.1 \%)$ \\
\hline Toxoplasma gondii & 0 & $4(0.6 \%)$ & NA & $8(1.2 \%)$ & $4(4 \%)$ & $3(0.4 \%)$ \\
\hline Salmonella sp. & $3(1.6 \%)$ & $2(0.3 \%)$ & NA & NA & NA & NA \\
\hline Nocardia sp. & $2(1.0 \%)$ & $23(3.7 \%)$ & $4(1.3 \%)$ & $2(0.3 \%)$ & NA & $2(0.2 \%)$ \\
\hline Cryptococcus & $2(1.0 \%)$ & $4(0.6 \%)$ & NA & $1(0.2 \%)$ & NA & $1(0.1 \%)$ \\
\hline
\end{tabular}

$\mathrm{NA}=$ not available.

${ }^{*} p<0.002$ between Hsu and Montoya and between Hsu and Miller by Fisher exact test.

${ }_{* *} p<0.001$ between Hsu and Montoya by Fisher exact test.

\section{Discussion}

\section{Mycobacterium tuberculosis}

The incidence of active tuberculosis infection in transplant recipients worldwide ranged from $0.18 \%$ to $15 \%(11-19)$. The diagnosis and effective management of tuberculosis after transplantation warrant recognition of the unique epidemiological and clinical characteristics of tuberculosis in transplant recipients. In Spain, the overall incidence of tuberculosis was $0.8 \%$ in all transplant recipients. The site of infection was pulmonary in $63 \%$ of the cases, disseminated in $25 \%$ and extrapulmonary in $12 \%$. Tuberculosis developed from 15 days to 13 years after transplantation (13). However, the prevalence of post-transplant tuberculosis is increasing globally and is high in Asia (15-19). Posttransplant tuberculosis occurs in $12-20 \%$ of renal transplant patients in India and results in the death of 20-25\% of those patients. Cyclosporine therapy, diabetes mellitus and chronic liver disease are risk factors for post-transplant tuberculosis $(15,16)$. The incidence of Mycobacterium tuberculosis infection in heart transplant recipients was low $(<1 \%)$ in western countries $(1,4,8,10,20)$. In our patients, the incidence of Mycobacterium tuberculosis infection was
$3.6 \%$, which is much higher than that reported in western countries. Tuberculosis is an endemic infectious disease in Taiwan (21).

\section{Cytomegalovirus}

Cytomegalovirus infection is a major cause of mortality and morbidity after heart transplantation (1-6). Data obtained from the Cardiac Transplant Research Database Group showed that the primary location of cytomegalovirus infection was blood in $43 \%$, lung in $30 \%$, gastrointestinal tract in $23 \%$ and other sites in $3 \%$. Risk factors for cytomegalovirus infection included pre-transplantation cytomegalovirus serology and use of cytolytic induction therapy (22). In our patients, although we used induction therapy in every patient, the incidence of post-transplant cytomegalovirus infection was less than $5 \%$. In addition, the most common manifestation of cytomegalovirus infection was the focal disease (5 of 9), not the most commonly disseminated form. Involvement of the retina occurred in 2 of 9 infected patients. In our study, donor cytomegalovirus seropositive rate was $93 \%$ and the recipient cytomegalovirus seropositive rate was $74 \%$. The high cytomegalovirus seropositive rate in Taiwan 
population contributes to low incidence of post-transplant cytomegalovirus disease and the predominance of focal disease. It also reduces the incidence of transplant coronary artery disease in Chinese heart recipients (7). However, the case recognization of post-transplant cytomegalovirus infection might be suboptimal because of the lack of the use of more sensitive virologic tests. Further study is needed to prove our point.

\section{Pneumocystis jiroveci pneumonia}

Pneumocystis jiroveci remains an important pathogen in patients who undergo solid organ and hematopoietic transplantation (1,23-27). The risk is greatest after lung transplants, in individuals with invasive cytomegalovirus disease, during intensive immunosuppression for acute rejection and during periods of neutropenia (23-27). The incidence of Pneumocystis jiroveci pneumonia during the first year following transplantation was higher than that during subsequent years (27). The incidence of Pneumocystis jiroveci pneumonia after heart transplantation varies according to the literature between $1 \%$ and $5 \%(1,4,5,8-10,23-25,28)$. Prophylaxis with trimethoprimsulfamethoxazole prevents many opportunistic infections, including infection with Pneumocystis jiroveci, Toxoplasma gondii and some community-acquired pathogens $(1,23-$ 25). Pneumocystis jiroveci infection occurred in patients who did not take or could not tolerate trimethoprimsulfamethoxazole as a prophylactic agent. Continued prophylaxis is recommended in high-risk recipients or in countries where Pneumocystis jiroveci infection is prevalent $(27,28)$. However, administration of trimethoprimsulfamethoxazole as prophylaxis for Pneumocystis jiroveci infection during the first year following transplantation has not been universally adopted. Waser et al. (9) reported a 4\% incidence of Pneumocystis jiroveci pneumonia among their heart transplant recipients despite the lack of routine use of trimethoprim-sulfamethoxazole. They suggest that this low incidence is related to a low prevalence of Pneumocystis jiroveci in the Swiss population and does not justify the routine use of trimethoprim-sulfamethoxazole prophylaxis.

In our study, only 14 patients (7\%) had trimethoprimsulfamethoxazole prophylaxis for Toxoplasma gondii infection after transplantation, and the incidence of Pneumocystis jiroveci pneumonia was extremely low $(<1 \%)$. Whether the prevalence of Pneumocystis jiroveci in the Chinese population is low or not is unknown. However, in Taiwan, Pneumocystis jiroveci pneumonia was a dominant cause of opportunistic infection in patients with human immunodeficiency virus infection (29) and in patients with bone marrow transplantation (19). In a case-control study performed in renal transplant recipients (30), the risk of Pneumocystis jiroveci pneumonia is related to the number and type of rejection treatments, to the occurrence of cytomegalovirus infection, to other infections such as tuberculosis and hepatitis $\mathrm{C}$ and to more potent immunosuppressive agents.
Patients who developed Pneumocystis jiroveci pneumonia while receiving trimethoprim-sulfamethoxazole prophylaxis were frequently coinfected with cytomegalovirus $(31,32)$, tuberculosis and bacterial pneumonia (30). Arend et al. (33) also reported that the risk of Pneumocystis jiroveci pneumonia in renal transplant recipients was positively related to rejection and cytomegalovirus infection. In our patients, the incidence of cytomegalovirus infection was low (4.7\%), and the incidence of Mycobacterium tuberculosis infection was high (3.6\%).

In summary, our heart transplant patients did not receive trimethoprim-sulfamethoxazole for Pneumocystis jiroveci prophylaxis. There was a significantly low incidence of Pneumocystis jiroveci pneumonia and cytomegalovirus infection, and high incidence of Mycobacterium tuberculosis infection in Taiwan.

\section{References}

1. Montoya JG, Giraldo LF, Efron B et al. Infectious complications among 620 consecutive heart transplant patients at Stanford University Medical Center. Clin Infect Dis 2001; 33: 629-640.

2. Robbins RC, Barlow CW, Oyer PE et al. Thirty years of cardiac transplantation at Stanford university. J Thorac Cardiovasc Surg 1999; 117: 939-951.

3. Brann WM, Bennett LE, Keck BM, Hosenpud JD. Morbidity, functional status, and immunosuppressive therapy after heart transplantation: an analysis of the joint International Society for Heart and Lung Transplantation/United Network for Organ Sharing Thoracic Registry. J Heart Lung Transplant 1998; 17: 374-382.

4. Miller LW, Naftel DC, Bourge RC et al. Infection after heart transplantation: a multiinstitutional study. Cardiac Transplant Research Database Group. J Heart Lung Transplant 1994; 13: 381-392.

5. Gentry LO. Cardiac transplantation and related infections. Semin Respir Infect 1993; 8: 199-206.

6. Smart FW, Naftel DC, Costanzo MR et al. Risk factors for early, cumulative, and fatal infections after heart transplantation: a multiinstitutional study. J Heart Lung Transplant 1996; 15: 329-341.

7. Hsu RB, Chu SH, Wang SS et al. Low incidence of transplant coronary artery disease in Chinese heart recipients. J Am Coll Cardiol 1999; 33: 1573-1577.

8. Cisneros JM, Munoz $\mathrm{P}$, Torre-Cisneros $\mathrm{J}$ et al. Pneumonia after heart transplantation: a multi-institutional study. Spanish Transplantation Infection Study Group. Clin Infect Dis 1998; 27: 324331.

9. Waser M, Maggiorini M, Luthy A et al. Infectious complications in 100 consecutive heart transplant recipients. Eur J Clin Microbio Infect Dis 1994; 13: 12-18.

10. Grossi P, De Maria R, Caroli A, Zaina MS, Minoli L. Infections in heart transplant recipients: the experience of the Italian heart transplantation program. Italian Study Group on Infections in Heart Transplantation. J Heart Lung Transplant 1992; 11: 847866.

11. Torre-Cisneros J, Caston JJ, Moreno J et al. Tuberculosis in the transplant candidate: importance of early diagnosis and treatment. Transplantation 2004; 77: 1376-1380.

12. Singh N, Paterson DL. Mycobacterium tuberculosis infection in solid-organ transplant recipients: impact and implications for management. Clin Infect Dis 1998; 27: 1266-1277. 


\section{Hsu et al.}

13. Aguado JM, Herrero JA, Gavalda J et al. Clinical presentation and outcome of tuberculosis in kidney, liver, and heart transplant recipients in Spain. Spanish Transplantation Infection Study Group, GESITRA. Transplantation 1997; 63: 1278-1286.

14. Cavusoglu C, Cicek-Saydam C, Karasu Z et al. Mycobacterium tuberculosis infection and laboratory diagnosis in solid-organ transplant recipients. Clin Transplant 2002; 16: 257-261.

15. Sakhuja V, Jha V, Varma PP, Joshi K, Chugh KS. The high incidence of tuberculosis among renal transplant recipients in India. Transplantation 1996; 61: 211-215.

16. John GT, Shankar V, Abraham AM, Mukundan U, Thomas PP, Jacob CK. Risk factors for post-transplant tuberculosis. Kidney Int 2001; 60: 1148-1153.

17. Yildiz A, Sever MS, Turkmen A et al. Tuberculosis after renal transplantation: experience of one Turkish centre. Nephrol Dial Transplant 1998; 13: 1872-1875.

18. Lee J, Lee MH, Kim WS et al. Tuberculosis in hematopoietic stem cell transplant recipients in Korea. Int J Hematol 2004; 79: 185188

19. Ku SC, Tang JL, Hsueh PR, Luh KT, Yu CJ, Yang PC. Pulmonary tuberculosis in allogeneic hematopoietic stem cell transplantation. Bone Marrow Transplant 2001; 27: 12931297.

20. Korner MM, Hirata N, Tenderich $\mathrm{G}$ et al. Tuberculosis in heart transplant recipients. Chest 1997; 111: 365-369.

21. Yu MC, Suo J, Huang C, Bai KJ, Lin TP, Luh KT. Annual risk of tuberculous infection in Taiwan, 1996-1998. J Formos Med Assoc 1999; 98: 496-499.

22. Kirklin JK, Naftel DC, Levine TB et al. Cytomegalovirus after heart transplantation. Risk factors for infection and death: a multiinstitutional study. The Cardiac Transplant Research Database Group. J Heart Lung Transplant 1994; 13: 394-404.

23. Fishman JA. Prevention of infection caused by Pneumocystis carinii in transplant recipients. Clin Infect Dis 2001; 33: 13971405
24. Olsen SL, Renlund DG, O'Connell JB et al. Prevention of Pneumocystis carinii pneumonia in cardiac transplant recipients by trimethoprim sulfamethoxazole. Transplantation 1993; 56: 359362.

25. Munoz P, Munoz RM, Palomo J, Rodriguez-Creixems M, Munoz $R$, Bouza E. Pneumocystis carinii infection in heart transplant recipients. Efficacy of a weekend prophylaxis schedule. Medicine 1997; 76: 415-422.

26. Roblot F, Le Moal G, Godet $\mathrm{C}$ et al. Pneumocystis carinii pneumonia in patients with hematologic malignancies: a descriptive study. J Infect 2003; 47: 19-27.

27. Gordon SM, LaRosa SP, Kalmadi S et al. Should prophylaxis for Pneumocystis carinii pneumonia in solid organ transplant recipients ever be discontinued? Clin Infect Dis 1999; 28: 240-246.

28. Cardenal R, Medrano FJ, Varela JM et al. Pneumocystis carinii pneumonia in heart transplant recipients. Eur J Cardiothorac Surg 2001; 20: 799-802.

29. Hung CC, Chen MY, Hsieh SM, Sheng WH, Chang SC. Clinical spectrum, morbidity, and mortality of acquired immunodeficiency syndrome in Taiwan: a 5-year prospective study. J Acquir Immune Defic Syndr 2000; 24: 378-385.

30. Radisic M, Lattes R, Chapman JF et al. Risk factors for Pneumocystis carinii pneumonia in kidney transplant recipients: a casecontrol study. Transpl Infect Dis 2003; 5: 84-93.

31. Grossi P, Ippoliti GB, Goggi C, Cremaschi P, Scaglia M, Minoli $\mathrm{L}$. Pneumocystis carinii pneumonia in heart transplant recipients. Infection 1993; 21: 75-79.

32. Costanzo-Nordin MR, Swinnen LJ, Fisher SG et al. Cytomegalovirus infections in heart transplant recipients: relationship to immunosuppression. J Heart Lung Transplant 1992; 11: 837-846.

33. Arend SM, Westendorp RG, Kroon FP et al. Rejection treatment and cytomegalovirus infection as risk factors for Pneumocystis carinii pneumonia in renal transplant recipients. Clin Infect Dis 1996; 22: 920-925 
Copyright of American Journal of Transplantation is the property of Blackwell Publishing Limited and its content may not be copied or emailed to multiple sites or posted to a listserv without the copyright holder's express written permission. However, users may print, download, or email articles for individual use. 